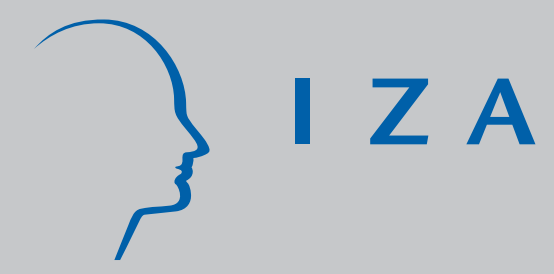

IZA DP No. 2385

The Aggregate Labor Market Effects of the Swedish Knowledge Lift Program

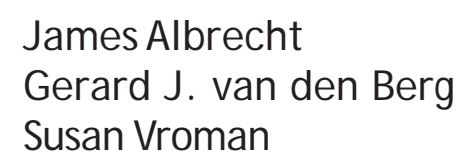

October 2006 


\title{
The Aggregate Labor Market Effects of the Swedish Knowledge Lift Program
}

\author{
James Albrecht \\ Georgetown University, IFAU Uppsala, \\ CESifo and IZA Bonn \\ Gerard J. van den Berg \\ Free University Amsterdam, IFAU Uppsala, \\ CEPR, IFS and IZA Bonn \\ Susan Vroman \\ Georgetown University, IFAU Uppsala, \\ CESifo and IZA Bonn
}

Discussion Paper No. 2385

October 2006

\author{
IZA \\ P.O. Box 7240 \\ 53072 Bonn \\ Germany \\ Phone: +49-228-3894-0 \\ Fax: +49-228-3894-180 \\ Email: iza@iza.org
}

\begin{abstract}
Any opinions expressed here are those of the author(s) and not those of the institute. Research disseminated by IZA may include views on policy, but the institute itself takes no institutional policy positions.

The Institute for the Study of Labor (IZA) in Bonn is a local and virtual international research center and a place of communication between science, politics and business. IZA is an independent nonprofit company supported by Deutsche Post World Net. The center is associated with the University of Bonn and offers a stimulating research environment through its research networks, research support, and visitors and doctoral programs. IZA engages in (i) original and internationally competitive research in all fields of labor economics, (ii) development of policy concepts, and (iii) dissemination of research results and concepts to the interested public.
\end{abstract}

IZA Discussion Papers often represent preliminary work and are circulated to encourage discussion. Citation of such a paper should account for its provisional character. A revised version may be available directly from the author. 
IZA Discussion Paper No. 2385

October 2006

\section{ABSTRACT}

\section{The Aggregate Labor Market Effects of the Swedish Knowledge Lift Program*}

The Swedish adult education program known as the Knowledge Lift (1997-2002) was unprecedented in its size and scope, aiming to raise the skill level of large numbers of lowskill workers. This paper evaluates the potential effects of this program on aggregate labor market outcomes. This is done by calibrating an equilibrium search model with heterogeneous worker skills using pre-program data and then forecasting the program impacts. We compare the forecasts to observed aggregate labor market outcomes after termination of the program.

JEL Classification: J21, J64, J31, J24, I21, C31

Keywords: job search, returns to education, program evaluation, wages, unemployment, Swedish labor market, calibration

Corresponding author:

Gerard J. van den Berg

Department of Economics

Free University of Amsterdam

De Boelelaan 1105

1081 HV Amsterdam

The Netherlands

E-mail: gjvdberg@xs4all.nl

\footnotetext{
* We thank IFAU for financial support. This paper builds on a section of the unpublished IFAU report "The Knowledge Lift: The Swedish Adult Education Program that Aimed to Eliminate Low Worker Skill Levels" (Albrecht, Van den Berg and Vroman, 2005). We thank Maria Melkersson, Håkan Regnér, PerAnders Edin, Katarina Richardson, Annette Bergemann, Bertil Holmlund, and seminar participants at IFAU/Uppsala University and conference participants in Louvain-la-Neuve, Florence (SED2004), IZA Bonn, and London (ESWC2005) for helpful comments and suggestions.
} 


\section{Introduction}

Life-long learning, adult education, and employability have become focal points in the labor market policies of many advanced economies (see e.g. the recent OECD Employment Outlook 2004). It is expected that these economies will face more turbulent conditions than in the past, and that the development of novel production technologies will proceed at a sustained high speed. This will require a flexible and suitably skilled workforce. Indeed, the role of low-educated workers has diminished in modern knowledge-based economies. The fact that there is now a heavier representation of older workers in the labor force means that the human capital adjustment needs to be made by the existing stock of workers rather than solely by the inflow of new workers.

Sweden is relatively well prepared for such a policy intervention, given its long tradition of training of adult unemployed workers (see e.g. Ministry of Education, 1998, Friberg, 2000, and Ministry of Industry, 2001). In 1997, Sweden implemented a new major adult education program called the "Adult Education Initiative" or "Knowledge Lift" (henceforth denoted as KL). Without exaggeration, this constitutes the largest and most ambitious skill-raising program ever. It aimed to raise the skill level of all low-skill workers to the medium-skill level. It focused on workers with a low level of education. The size of the program was unprecedented: in the period 1997-2000 alone, more than 10\% of the labor force participated in it.

Obviously, the program reflected a great deal of optimism about the extent to which an adult's human capital can be improved. The empirical literature on training programs for unemployed workers does not warrant this optimism. The general conclusion from this literature is that training does not have large effects on the individual's labor market outcomes (see e.g. Fay, 1996, Heckman, LaLonde and Smith, 1999, and Martin and Grubb, 2001). A potential exception concerns training for women who return to the labor market after a spell of childraising activity, who clearly form an important target group for adult education. However, perhaps more importantly, training participants with a low initial level of education benefit even less than other educational groups.

While this evidence questions the presence of effects on individual outcomes, it is still possible with a large training program such as KL that there are macroeconomic labor market effects. In this paper, we analyze these macroeconomic effects of KL. Specifically, we examine the equilibrium effects of KL by calibrating an equilibrium matching model with labor market frictions and skill heterogeneity. Given the size of the program, equilibrium effects may be substantial. In addition 
to any effect on the individuals in the program, other workers in the economy are likely to be impacted through changes in wages and/or through changes in unemployment and employment probabilities. ${ }^{1}$ Obviously, the model we use should incorporate skill heterogeneity and equilibrium unemployment. Also, firms should be able to choose their production technology in the face of the prevailing skill distribution. We use a model based on Albrecht and Vroman (2002), which is a concise and amenable model satisfying the above requirements. It assumes two worker types, low skill and medium skill, with the number of workers of each type taken as exogenous in a given market. There are frictions in the process by which unemployed workers and vacancies contact one another, and the surplus generated by a worker/job match is divided using the Nash bargaining solution. The flow output of a match depends on the skill level of the worker as well as on the job type as decided by the firm when it created the vacancy.

We use macro data from 1996 to calibrate the pre-KL economy. This allows us to set values for the unobserved parameters that drive the theoretical model. We then address the question: "Suppose KL were to change the skill distribution in the economy in a particular way. Using the calibrated economy as a base, what would the effects be?" Specifically, we impute potential post-KL skill distributions and solve the model for the new steady-state equilibria. We derive wages for low-skill and medium-skill workers as well as their unemployment rates and employment in low-skill and medium-skill jobs. We also derive the overall unemployment rate, labor market tightness (vacancies over unemployment), the proportions of low-skill and medium-skill vacancies, and the equilibrium effects on the treated. Since the model we use is a steady-state model, the aggregate effects it predicts should be long-run effects. KL ran until/including 2002. Nonetheless, we look at early post-KL data to see what aggregate labor market effects have occurred between 1996 and 2004 .

In addition to the aggregate labor market effects that we analyze, KL may have had other effects on the economy. For example, Björklund et al. (2004) show that KL generated a large flow of teachers from regular secondary education to adult education, and they argue that KL therefore may have generated substantial negative external effects on the quality of regular education. However, addressing these effects is beyond the scope of our paper. We also do not aim to address the use of adult education by young individuals who left the regular school system with low educational levels, as a short-cut towards regular university education (see e.g. Björklund et al., 2004, and Ekström, 2003, for discussions). For this

\footnotetext{
${ }^{1}$ See e.g. Lise, Seitz and Smith (2002) for a general discussion of equilibrium evaluation of policy programs.
} 
reason we exclude individuals aged below 25 in our calibration.

The paper is organized as follows. Section 2 describes the KL program. In Section 3, we describe the equilibrium model that is the basis for the calibration. Section 4 describes the data used to calibrate the model and gives the results of the calibration. Section 5 contains the results of the equilibrium analysis and a discussion of aggregate labor market changes between 1996 and 2004, while Section 6 concludes.

\section{The Knowledge Lift}

As explained below, KL was run through the existing municipal adult education system (KOMVUX) and can be seen as a major qualitative and quantitative upscaling of KOMVUX. By now, many studies provide detailed descriptions of KL and/or KOMVUX and their participants. See, for example, The National Agency for Education (1999), Axelsson and Westerlund (1999), Skolverket (2001), and Stenberg (2003) for information on KL, and Skolverket (2001) and Ekström (2003) for information on KOMVUX. We therefore restrict ourselves here to a brief summary.

KL was by far the largest adult education program ever in Sweden. It ran from July 1, 1997 to December 31, 2002. The objective was to increase the skill level of adult low-skill workers to the medium skill level, thereby helping these individuals strengthen their position in the labor market. Here, low skill means having an educational attainment below the level of a 3-year "gymnasium" degree, while medium skill means having attained this level but not any levels beyond that. The 3-year gymnasium degree roughly corresponds to the upper secondary education level or senior high school. Since 1995 this is the lowest possible upper secondary school diploma, whereas before that many individuals left high school with a 2-year degree. The program particularly targeted unemployed adult lowskill workers. However, low-skill employed workers and medium-skill unemployed workers were also often eligible for KL, and the enrollees included many low-skill employed workers, working part time or full time.

Due to KL, the number of individuals in adult education became dramatically larger than in earlier years (the increase in the stock of participants was about $80 \%$ ). The old KOMVUX system included courses that were not aimed at the attainment of a medium skill level but rather an improvement within the class of low skill sublevels. Compared to the old KOMVUX system, KL also involved the improvement and modernization of teaching methodologies and pedagogy. For all practical purposes, KL and KOMVUX were indistinguishable in the period in 
which KL ran. Therefore, in the remainder of the paper, we simply refer to KL as the program we evaluate.

KL focused on the enhancement of general skills (for example, English, Swedish, and mathematics), as opposed to specific skills needed for particular professions. However, part of KL could be used for vocational courses and work placement. In principle, it was possible to combine upper secondary courses with studies at an elementary level or with a program organized by the National Labor Market Board for the unemployed. The curricula and grade criteria for the attainment of the medium skill level were roughly the same as in the regular upper secondary education system.

KL was organized at the municipal level and run through the KOMVUX system. It was possible for the organization to be joint among several municipalities. A municipality could purchase the services of education providers and/or cooperate with them. However, the municipalities were responsible for admission into KL. A single course typically started twice a year and covered a half-year term.

At the level of the individual, admission into KL was in principle unrestricted. The underlying view was that KL participation should be led by the demand for education. A participant should have ample scope for personal choice regarding the type of study and its timing and location. Whether one could participate in a desired course only depended on the availability of courses and on the entry skill level requirement. Recruitment of participants was sometimes carried out in cooperation with trade union organizations or local employment offices.

KL participants were eligible for a range of income grants and financial study support measures. Some enrollees received "special education support" (UBS). The amount of financial support was equivalent to unemployment insurance (UI). UBS was only given to KL participants who were entitled to UI payments at date of entry into the program. Moreover, the worker had to be between 25-55 years old inclusive at date of entry into the program and had to study at the elementary or upper secondary level. The grant was typically given for a maximum of one year. Sometimes, special adult study assistance and funding were available as a combination of a grant and a loan. Many participants relied on other financial resources. An individual who was full-time in KL was considered to be out of the labor force unless he/she earned income on the side.

The state channeled funds to the municipalities to finance KL. The amount of funding depended on the municipality's unemployment rate and skill level distribution, and on the scope of the municipality's program. A conservative estimate is that, in the first years of its existence, the state spent at least SEK 3.5 billion per year on KL. This equaled almost SEK 1000 per labor force participant 
in Sweden. The spending covered the creation of some 100,000 annual study slots. In practice, the funding was more than sufficient to meet the demand for KL (see Statskontoret, 1999). This fact is important for our analysis because it implies that there was no quantity rationing.

The following gives an indication of the size of the program in terms of numbers of enrollees. In the fall of 1997, 538,004 individuals (out of a population of $8 \mathrm{M}$ ) were (i) aged between 25 and 55, and (ii) participated in the municipal adult education, or were unemployed (in the sense of actively searching), or participated in one or more training programs. About 220,000 of these participated in KL, and of these about 56,000 received UBS. About 35,000 KL participants were registered as unemployed, and another 5,000 participated both in KL and in employment training. The number of registered unemployed, including those participating in KL and/or training programs was about 330,000. For comparison, the number of pupils in regular upper secondary school was about 300,000, while the number of individuals participating in employment training programs was about 40,000. The figures do not sum to the total of 538,004 because some individuals fall into more than one category. Typically, the number of individuals enrolled in KL is about $50 \%$ larger than the full-time equivalent of the number of occupied slots. This indicates that many enrollees were part-time participants. Skolverket (2001) provides a wealth of additional information on the composition of participants and courses.

\section{The Model}

As indicated in the introduction, we use the equilibrium labor market model from Albrecht and Vroman (2002). We first present a generalization of that model. Then we calibrate it using pre-program data.

The model is a stylized one in which risk-neutral workers live forever. The measure of workers is normalized to 1 . The skill distribution is taken as exogenous and we denote the fraction of the labor force with skill level $s_{i}$ as $p_{i}$ with $\sum_{i=1}^{S} p_{i}=1$. Jobs are described by their minimum skill requirement, $y$. The technology is such that the output produced by a job of type $y$ with a worker of skill $s$ is $x(s, y)=\left\{\begin{array}{lll}y & \text { if } \quad s \geqslant y \\ 0 & \text { if } \quad s<y\end{array}\right.$.

A job is either vacant or filled. When a job of type $y$ is filled by a worker of skill $s$, a wage of $w(s, y)$ is paid and a cost of $c_{y}$ is incurred. That is, the flow value to the firm of filling a job of type $y$ with a worker of skill $s$ is $y-w(s, y)-c_{y}$, 
conditional, of course, on $s \geqslant y$. The corresponding flow value to the worker holding the job is the wage. When a job is vacant, the fixed cost must still be paid so the flow value of a vacancy of type $y$ is $-c_{y}$. The corresponding flow value to an unemployed worker is $b$, which can be interpreted as unemployment compensation and/or the value of not working.

Matches break up (filled jobs become vacant) at the rate $\delta_{y}$, i.e., we assume that job stability varies by job type (this, as well as the dependence of $c$ on $y$, generalizes Albrecht and Vroman, 2002). The flow in the opposite direction is governed by a matching function. Specifically, unemployed workers and vacancies match randomly according to a constant returns to scale matching function

$$
m(u, v)=m\left(1, \frac{v}{u}\right) u=m(\theta) u, \text { where } \theta=\frac{v}{u}
$$

with $m^{\prime}(\theta)>0$ and $d\left(\frac{m(\theta)}{\theta}\right) / d \theta<0$.

We use the following notation:

$U(s)$ is the value of unemployment for a worker of skill $s$

$N(s, y)$ is the value of employment for a worker of skill $s$ on a job of type $y$

$V(y)$ is the value of a vacancy of type $y$,

$J(s, y)$ is the value to an employer of filling a job of type $y$ with a worker of skill $s$.

A match will be formed if and only if

$$
N(s, y)+J(s, y) \geqslant U(s)+V(y)
$$

and when a match is formed, the wage, $w(s, y)$, is given by the Nash bargaining condition,

$$
N(s, y)-U(s)=\beta[N(s, y)+J(s, y)-U(s)-V(y)]
$$

where $\beta$ is the exogenously given worker's share of the surplus.

We assume free entry and exit of vacancies, so in equilibrium, there will be at most $S$ skill requirements: $y_{j}=s_{j}, j=1, \ldots, S$. We define $\phi_{j}$ to be the fraction of vacancies requiring skill $s_{j}$ and $\gamma_{i}$ to be the fraction of the unemployed who have skill $s_{i}$. The unemployment rate, $u$, labor market tightness, $\theta$, and the fractions $\left\{\phi_{j}\right\}_{j=1}^{S}$ and $\left\{\gamma_{i}\right\}_{i=1}^{S}$ are the fundamental endogenous variables of the model.

The value functions for filled jobs are

$$
\begin{aligned}
r N\left(s_{i}, s_{j}\right) & =w\left(s_{i}, s_{j}\right)+\delta_{j}\left[U\left(s_{i}\right)-N\left(s_{i}, s_{j}\right)\right] \\
r J\left(s_{i}, s_{j}\right) & =s_{j}-w\left(s_{i}, s_{j}\right)-c_{j}+\delta_{j}\left[V\left(s_{j}\right)-J\left(s_{i}, s_{j}\right)\right]
\end{aligned}
$$


Both of these are conditional on $s_{i} \geq s_{j}$. The value of unemployment for a worker of skill $s_{i}$ is

$$
r U\left(s_{i}\right)=b+m(\theta) \sum_{j \leq i} \phi_{j} \max \left[N\left(s_{i}, s_{j}\right)-U\left(s_{i}\right), 0\right]
$$

and the value of a vacancy of type $s_{j}$ is

$$
r V\left(s_{j}\right)=-c_{j}+\frac{m(\theta)}{\theta} \sum_{j \leq i} \gamma_{i} \max \left[J\left(s_{i}, s_{j}\right)-V\left(s_{j}\right), 0\right]
$$

Free entry and exit of vacancies implies $V\left(s_{j}\right) \leq 0$, with equality if $\phi_{j}>0$, $j=1, \ldots, S$.

The above expressions imply that a match will be formed if and only if

$$
s_{j}-c_{j} \geqslant r U\left(s_{i}\right)
$$

and the wage of a worker of skill $s_{i}$ on a job requiring skill $s_{j}$ is

$$
w\left(s_{i}, s_{j}\right)=\beta\left(s_{j}-c_{j}\right)+(1-\beta) r U\left(s_{i}\right) .
$$

Both of these are conditional on $s_{i} \geq s_{j}$. Note that this allows for wage dispersion both within and across worker types.

We look for steady-state equilibria. A steady-state equilibrium is a collection of variables $u, \theta,\left\{\phi_{j}\right\}_{j=1}^{S}$, and $\left\{\gamma_{i}\right\}_{i=1}^{S}$ such that (i) the appropriate steady-state conditions hold, (ii) there is free entry and exit of vacancies, i.e., $V\left(s_{j}\right) \leq 0(=0$ if $\phi_{j}>0$ ), and (iii) matches form iff $s_{j}-c_{j} \geq r U\left(s_{i}\right)$. Several equilibrium types are possible. For example, one might consider an equilibrium in which workers at each skill level match only with vacancies requiring precisely that skill, i.e., an equilibrium with perfect assortative matching. We refer to this case as equilibrium with ex post segmentation. At the other extreme, an equilibrium might entail all possible matches; i.e., a worker of skill $s_{i}$ could match with any job of type $s_{j} \leq s_{i}$. We refer to this case as equilibrium with full cross-skill matching. Intermediate cases, in which some but not all possible matches are formed, are also possible.

The nature of equilibrium depends on the exogenous parameters of the model. If an equilibrium of a particular type exists, e.g., an equilibrium with ex post segmentation, then that equilibrium is unique within that class. There may, however, be multiple equilibria in the sense that equilibria of more than one type can exist simultaneously.

In our analysis of KL, we consider only two skill levels, low and medium, and model KL as moving low-skill workers to the medium skill level, i.e., as a 
change in the proportions of the labor force in the various skill categories. We ignore high-skill workers on the assumption that they are unaffected by KL. We assume that before KL, the labor force has a particular skill distribution, and the market is in the corresponding steady-state equilibrium. We use pre-KL data to calibrate this equilibrium. After $\mathrm{KL}$, the labor force has another skill distribution, with more medium-skill workers and fewer low-skill workers. In the next section, we simulate the new labor market equilibrium on the basis of possible new skill distributions using the structural parameters obtained in the calibration. Comparison of the equilibrium outcomes is informative about the equilibrium effects of KL for various worker types. We are particularly interested in the changes in outcomes for individuals who were previously low skill and currently medium skill.

A theoretical analysis of the transition path between the equilibria is infeasible. Also, a comparative statics exercise that compares two equilibria cannot be translated into a sequence of actions and reactions by individual agents. However, from the above model we can get some idea about the underlying mechanisms. With more medium-skill workers, the rate at which employers contact them increases. Similarly, the rate at which low-skill workers are contacted decreases. This provides an incentive for employers to create medium-skill jobs rather than low-skill jobs. Labor demand thus adjusts to labor supply. The extent to which this occurs depends on the parameters of the model and on the assumed specification of the production function. Simultaneously, labor market tightness, the transition rates from unemployment to employment by worker-skill level, the unemployment rate, and the wage rates by worker/job-skill combination change. Again the results depend on the model parameters and functions.

It is important to point out that we do not assume that KL has a direct effect on the individual contact rate for a given skill level in a given equilibrium. So in this sense there is no causal "job search assistance" effect on the transition rates to work. However, individuals who are treated in KL qualify for a different set of jobs in the new equilibrium. In addition, since KL affects the proportions of low-skill workers and low-skill jobs, there is an indirect effect on the transition rates to work even for individuals who do not change skill level. 


\section{Calibration to Pre-Program Data}

\subsection{Data for the calibration}

The data we use are for 1996, the year before the start of KL, and are taken from publications from Statistics Sweden. In particular, we use data from the Swedish labor force survey (AKU) and from the Swedish wage statistics yearbook (Lönestatistisk Årsbok), which gives wage data aggregated from firm records (see Statistics Sweden, 1997a, 1997b).

For our calibration, we use two skill levels, namely, low-skill $\left(s_{1}\right)$ and mediumskill $\left(s_{2}\right)$. We assume exogenous skill fractions, identifying skill with educational attainment. We take those with less education than a 3-year gymnasium degree, i.e., SUN Codes 1, 2 and 3, to be low-skill and those with a 3-year gymnasium degree (SUN Code 4) and those with less than 3 years of post-gymnasium education (SUN Code 5) to be medium-skill ${ }^{2}$. AKU Tables 43 and 48 provides observations for labor force participants and unemployed aged 25-64 by SUN Codes.

\section{Unemployment}

\begin{tabular}{|c|c|c|c|c|c|c|}
\hline SUN Codes & 1 & 2 & 3 & 4 & 5 & Total \\
\hline LF in 100's & 4320 & 4544 & 12346 & 5870 & 5649 & 32729 \\
\hline U in 100's & 398 & 431 & 996 & 448 & 249 & 2522 \\
\hline U rates & .092 & .095 & .081 & .076 & .044 & .077 \\
\hline
\end{tabular}

These imply that $p_{1}=0.648$ and $p_{2}=0.352$. In addition, the fraction of unemployment accounted for by low-skill workers $\gamma_{1}$ equals $\frac{398+431+996}{2522}=0.724$ (implying that $\gamma_{2}=0.276$ ), and the average skill-specific unemployment rates are $u_{1}=0.086$ and $u_{2}=0.060$.

We also quantify the exit rates out of unemployment for the two skill groups. For this we use AKU Table 49, giving the elapsed unemployment duration distribution by skill. Our model assumes exponential duration distributions. The exponentiality assumption helps us in two ways. We have data on elapsed, as opposed to completed, durations. The exponential assumption implies that these two distributions, i.e., of elapsed and completed durations, are the same. Second, if $\xi$ is the median of an $\exp \{\lambda\}$ distribution, then $\lambda=\frac{\ln 2}{\xi}$, i.e., we can use the

\footnotetext{
${ }^{2}$ SUN stands for Swedish Education Level. There are 7 SUN codes. Category 6 is 3 or more years of post-gymnasium eduction and category 7 is doctoral education. We assume there is no interaction between the labor markets for workers in these higher skill levels and those that we call medium skill. We attempted to calibrate a three-skill level model extension, but the data appeared to be inconsistent with such a model.
} 
median of the elapsed duration distribution to estimate the exponential parameter. As a result, the exit rates out of unemployment for low and medium skills equal 1.867 and 2.163, respectively, in per-year terms.

Using the "Totalt" column of Table 4 of Lönestatistisk Årsbok 1996, we specify the wages as $w_{11}=177,600, w_{21}=186,000, w_{22}=210,000$, where $w_{i j}$ is a shorthand for $w\left(s_{i}, s_{j}\right) .^{3}$

\subsection{The calibration of the pre-KL equilibrium}

Since we are considering a model with 2 skill levels, there are 2 possible equilibrium configurations, namely

1. Cross-skill matching: In this equilibrium, medium-skill workers match with both medium-skill and low-skill vacancies. Low-skill workers match only with low-skill vacancies.

2. Ex-post segmentation: In this equilibrium, medium-skill workers match only with medium-skill vacancies, and low-skill workers match only with low-skill vacancies.

The large amount of variation in the wage data for medium-skill workers fits better with the first configuration. Indeed, in Appendix 1 we demonstrate that calibration of the second configuration provides nonsensical results. We therefore base our analysis on the cross-skill matching equilibrium.

The first step in the calibration is to use the exit rates from unemployment and the steady-state conditions to identify the flow parameters, namely, $\delta_{1}, \delta_{2}, \phi_{1}, \phi_{2}$, and the contact rate, $m(\theta)$. The first steady-state condition is that the flow of low-skill workers into low-skill employment equals the flow of low-skill workers back into unemployment. This can be expressed as

$$
\phi_{1} m(\theta) \gamma_{1} u=\delta_{1} e_{11}
$$

where $e_{11}$ is the fraction of the labor force accounted for by employment of lowskill workers in low-skill jobs. Given our estimated exit rates and data on unemployment by skill level, we know the value of the left-hand side of this equation. Further, since $e_{11}=p_{1}-\gamma_{1} u$, we can compute the remaining unknown in this first steady-state equation, namely, $\delta_{1}$. The second steady-state condition is that the

\footnotetext{
${ }^{3}$ The wage data are presented at the 10th, 25th, 50th, 75th and 90th percentile for each SUN category, so the figures we have chosen for the $w_{i j}$ are necessarily educated guesses.
} 
flow of medium-skill workers into low-skill employment equals the corresponding flow from low-skill employment back into unemployment,

$$
\phi_{1} m(\theta) \gamma_{2} u=\delta_{1} e_{21}
$$

This condition gives us $e_{21}$, the fraction of the labor force accounted for by medium-skill workers employed in low-skill jobs. Next, the flow of mediumskill workers into medium-skill employment equals the corresponding flow from medium-skill employment back into unemployment. That is,

$$
\phi_{2} m(\theta) \gamma_{2} u=\delta_{2} e_{22}
$$

We know $e_{21}+e_{22}$, i.e., total employment of medium-skill workers. We know $e_{21}$ from the second steady-state condition, so we know $e_{22}$. The third steady-state condition thus gives us $\delta_{2}$.

Finally, we know that $\phi_{1}+\phi_{2}=1$. Since we know the exit rates from unemployment for each skill group, we can recover $m(\theta), \phi_{1}$, and $\phi_{2}$. It may be possible at this point to use the requirement that each $\phi_{i} \in[0,1]$ to rule out some equilibrium possibilities.

In the second step, we set values for $b$ and $r$. For our specific application, we assume that $b=80000$ and $r=0.05$. Given the three wage equations

$$
w\left(s_{i}, s_{j}\right)=\beta\left(s_{j}-c_{j}\right)+(1-\beta) r U\left(s_{i}\right) \text { for } s_{i} \geq s_{j}
$$

and the expression for $r U\left(s_{1}\right)$, we can solve for $s_{1}-c_{1}, s_{2}-c_{2}, r U\left(s_{1}\right), r U\left(s_{2}\right)$, and $\beta$.

At this point, we need to check that the relevant conditions on these values for a cross-skill matching equilibrium type hold, namely,

$$
\begin{aligned}
& s_{1}-c_{1} \geq r U\left(s_{2}\right) \\
& s_{1}-c_{1} \geq r U\left(s_{1}\right) \\
& s_{2}-c_{2} \geq r U\left(s_{2}\right) .
\end{aligned}
$$

If these are not satisfied then the parameters of the model are inconsistent with this type of equilibrium.

The third step of our calibration strategy is to use the zero-value conditions to recover the cost parameters and the parameters of the matching function. At this point, we need to fix two more parameters. We assume a Cobb-Douglas matching function, so $m(\theta)=A \theta^{\alpha}$, and we choose plausible values for $A$ and $\alpha$. We choose $\alpha=0.5$, with reference to estimates from the empirical literature on matching functions (e.g., Petrongolo and Pissarides 2001). The choice of $A$ is 
more arbitrary, but since we have already recovered $m(\theta)$ from the first step of our procedure, a choice of $A$ is equivalent to choosing $\theta$. Since the numerator of $\theta$ (i.e., the measure of vacancies) is difficult to quantify, this can be viewed as a normalization. We take $A=5$.

Finally, the zero-value conditions for the relevant equilibrium type give us $c_{1}$ and $c_{2}$. We would naturally like $c_{1}<c_{2}$ and $s_{1}<s_{2}$.

We now give the results. The exit rates from unemployment are

$$
\begin{array}{|l|}
\hline m(\theta) \phi_{1}=1.867 \\
\hline m(\theta)\left(\phi_{1}+\phi_{2}\right)=m(\theta)=2.163 . \\
\hline
\end{array}
$$

These imply

$$
\begin{array}{|l|l|l|}
\hline m(\theta)=2.163 & \phi_{1}=0.863 & \phi_{2}=0.137 \\
\hline
\end{array}
$$

Putting these values into the steady-state conditions allows us to recover the jobspecific exit rates and the skill composition of employment as described above. These are

\begin{tabular}{|c|c|c|c|c|}
\hline$\delta_{1}$ & $\delta_{2}$ & $e_{11}$ & $e_{21}$ & $e_{22}$ \\
\hline .176 & .059 & .592 & .225 & .106 \\
\hline
\end{tabular}

Subsequently, from step 2,

\begin{tabular}{|c|c|c|c|c|}
\hline$s_{1}-c_{1}$ & $s_{2}-c_{2}$ & $r U\left(s_{1}\right)$ & $r U\left(s_{2}\right)$ & $\beta$ \\
\hline 190020 & 242290 & 167064 & 182593 & .45911 \\
\hline
\end{tabular}

Note that the inequalities required for cross-skill matching are satisfied.

Finally, we solve for $\theta, c_{1}, c_{2}, s_{1}$, and $s_{2}$. Given $m(\theta)=2.163$, our choice of $\alpha$ and $A$ implies $\theta=0.187$ and $\frac{m(\theta)}{\theta}=11.56$. We recover the cost parameters from the zero-value conditions. This gives

\begin{tabular}{|c|c|c|c|c|}
\hline$\theta$ & $c_{1}$ & $c_{2}$ & $s_{1}$ & $s_{2}$ \\
\hline .187 & 516612 & 945003 & 706632 & 1187293 \\
\hline
\end{tabular}

This solution ranks the cost and productivity parameters in the desired order.

Before turning to the simulations of KL, note that our calibration rsults can be used to assess the effects of upgrading the skill level of a single low-skill individual to the medium skill level. In a market with a continuum of workers the upgrading has no measurable effects on the other agents, and we restrict attention to the effects on outcomes for the individual under consideration. We may call these 
the "partial" effects of a skill-raising program. They do not have an empirical counterpart, but as we shall see they are helpful to understand the equilibrium effects.

For such an individual, the average wage changes from $w_{11}$ to the mean wage among medium-skill workers $\left(\sum_{j} e_{2 j} w_{2 j} / \sum_{j} e_{2 j}\right)$, which is an increase of 16086 . The average unemployment rate changes from $u_{1}$ to $u_{2}$, i.e. it decreases by 2.6 percentage points. This difference is partly due to the fact that medium-skill jobs have a much lower job separation rate than low-skill jobs, and partly due to the higher exit rate out of unemployment for medium-skill workers. Subsequently, it can be deduced that the average annual income (which is a weighted average of $b$ and the average wage) increases by 17640 . This exceeds the effect on the average wage, despite the fact that income in unemployment is independent of skill level. This is of course due to the dominating reduction of the average amount of time spent unemployed.

\section{Simulation of KL and Comparison with Post- Program Data}

\subsection{Simulation of KL}

In our simulations, we suppose that KL reduces the proportion of low-skill workers from $p_{1}=.648$ to .60 and then to .55 . We feel that this captures the magnitude of the change in skill levels that KL could potentially have produced. We keep the other structural parameters fixed at the values obtained in the last section, i.e., $r=0.05, b=80000, m(\theta)=5 \theta^{.5}, \delta_{1}=0.176, \delta_{2}=0.059, c_{1}=516612$, $c_{2}=945003, s_{1}=706632, s_{2}=1187293$. In Appendix 2 we derive the equations that must be solved for the simulation. The results of our simulations are given below. We first discuss the equilibrium effects on aggregate outcomes and then the equilibrium effects at the individual level.

Baseline with $p_{1}=.648$ and $p_{2}=.352$

\begin{tabular}{|c|c|c|c|c|c|c|c|c|}
\hline$\theta$ & $m(\theta)$ & $u$ & $u_{1}$ & $u_{2}$ & $\gamma_{1}$ & $\gamma_{2}$ & $\phi_{1}$ & $\phi_{2}$ \\
\hline .187 & 2.163 & .077 & .086 & .060 & .724 & .276 & .863 & .137 \\
\hline \hline$e_{11}$ & $e_{21}$ & $e_{22}$ & $w_{11}$ & $w_{21}$ & $w_{22}$ & & \\
\cline { 1 - 6 } .592 & .225 & .106 & 176000 & 186000 & 210000 & & \\
\end{tabular}

Simulation with $p_{1}=.6$ and $p_{2}=.4$

\begin{tabular}{|c|c|c|c|c|c|c|c|c|}
\hline$\theta$ & $m(\theta)$ & $u$ & $u_{1}$ & $u_{2}$ & $\gamma_{1}$ & $\gamma_{2}$ & $\phi_{1}$ & $\phi_{2}$ \\
\hline .180 & 2.122 & .078 & .092 & .056 & .710 & .290 & .829 & .171 \\
\hline
\end{tabular}




\begin{tabular}{|c|c|c|c|c|c|}
\hline$e_{11}$ & $e_{21}$ & $e_{22}$ & $w_{11}$ & $w_{21}$ & $w_{22}$ \\
\hline .545 & .222 & .155 & 176790 & 188270 & 212270 \\
\hline
\end{tabular}

Simulation with $p_{1}=.55$ and $p_{2}=.45$
\begin{tabular}{|c|c|c|c|c|c|c|c|c|}
\hline$\theta$ & $m(\theta)$ & $u$ & $u_{1}$ & $u_{2}$ & $\gamma_{1}$ & $\gamma_{2}$ & $\phi_{1}$ & $\phi_{2}$ \\
\hline .174 & 2.083 & .079 & .099 & .053 & .695 & .305 & .778 & .222 \\
\hline \hline$e_{11}$ & $e_{21}$ & $e_{22}$ & $w_{11}$ & $w_{21}$ & $w_{22}$ & & \\
\hline .495 & .217 & .209 & 175890 & 190400 & 214400 &
\end{tabular}

The results show that a program such as KL that moves workers from low to medium skills can have important equilibrium effects. The first-order equilibrium effect comes via the equilibrium change in job composition. As the fraction of medium-skill workers in the labor force increases, the fraction of vacancies tailored towards those workers increases commensurately. In our simulations, increases in $p_{2}$ translate almost one-for-one into increases in $\phi_{2}$. The measure of low-skill workers employed in low-skill jobs $\left(e_{11}\right)$ also falls by about the same amount. There is a slight decrease in the measure of medium-skill workers employed in low-skill jobs $\left(e_{21}\right)$. On the one hand, there are more medium-skill workers; on the other hand, there are fewer low-skill jobs. In our simulations, the second effect dominates slightly. Finally, the increase in the measure of medium-skill workers employed in medium-skill jobs increases by about the same amount as the fraction $p_{2}$ does.

The effect of a change in skill composition on aggregate unemployment is small. This is partly because the change in labor market tightness is small. The variable $\theta$ falls slightly, meaning that workers in general take a bit longer to locate a vacancy. However, there are important distributional effects on unemployment across the two skill categories. There are more medium-skill workers, and these workers on average find jobs more quickly and on average retain them longer than low-skill workers do. Unemployment even decreases among the fraction of medium-skill workers who have always been medium-skill, because, even though $m(\theta)$ falls slightly, there are relatively more medium-skill jobs which are on average kept longer. At the same time, the remaining low-skill workers have more difficulty finding a job than they did before the policy change. The reason is again the shift in job composition - relatively fewer low-skill vacancies are being opened ( $\phi_{1}$ falls). The fraction of unemployment accounted for by medium-skill workers, $\gamma_{2}$, increases simply because there are now more medium-skill workers.

There is also a clear effect on the distribution of wages. The wages of low-skill workers fall whereas the wages of medium-skill workers increase on both low- and medium-skill jobs. This reflects the change in unemployment values for the two 
Table 1: Equilibrium average treatment effects if $K L$ changes the relative measures of low and medium skilled from 0.65 to 0.55 and from 0.35 to 0.45 , respectively.

\begin{tabular}{|l|c|c|c|}
\hline \hline outcome measure: & $\begin{array}{c}\text { average } \\
\text { wage }\end{array}$ & $\begin{array}{c}\text { employment } \\
\text { probability }\end{array}$ & $\begin{array}{c}\text { average } \\
\text { income }\end{array}$ \\
\hline & 178 & 0.914 & 169 \\
$(a)$ pre-KL, low skill & 194 & 0.940 & 187 \\
(b) pre-KL, medium skill & & & \\
& 176 & 0.901 & 166 \\
(c) post-KL, low skill & 202 & 0.947 & 196 \\
$(d)$ post-KL, medium skill & & & \\
& & & \\
"partial" treatment effect on treated: $b$ minus $a$ & 16 & 0.026 & -3 \\
equil. change for remaining low skilled: $c-a$ & -2 & -0.013 & 9 \\
equil. change for remaining medium skilled: $d-b$ & 8 & 0.007 & 27 \\
equil. change for treated: $d-a$ & 24 & 0.033 & 29 \\
equil. treatment effect: $(d-a)-(c-a)$ & 26 & 0.046 & \\
& & & \\
\hline \hline
\end{tabular}

Note: monetary variables are annual averages in 1000 SEK (1996 level).

worker types. The value of unemployment among low-skill workers falls because these workers now take longer on average to find a job; the value of unemployment among medium-skill workers increases because these workers now face a better mix of job opportunities.

We next consider equilibrium effects at the inividual level. The top panel of Table 1 summarizes the average wage, employment, and income outcomes, before and after KL, and by skill level. These are subsequently used to quantify the changes in outcomes for those who stay low skill, those who stay medium skill, and those whose skills are upgraded, in the bottom panel of the table. For completeness we also list "partial" effects, which capture the change in outcomes in absence of equilibrium effects, like for an individual whose skill level is upgraded while all other individuals' skill levels remain unchanged. The last row of Table 1 gives the effects on the outcomes for the low-skill individuals whose 
skills are actually upgraded, by comparing them to the post-program outcomes of the individuals whose skills are not upgraded. These are the counterparts of the difference-in-differences and the conditional probit analysis found in the microeconometric evaluation literature. They may be called the average equilibrium treatment effects on the treated.

The rows in the top panel of the table display the same ranking for each outcome measure: $c<a<b<d$. This confirms for each outcome measure that the treated gain most from the program. Those who have always been medium skill also benefit, whereas the remaining low skill suffer. Moreover, the equilibrium effects are always a factor 1.5 to 2 times larger than the "partial" effects. Again, this is because the program generates an equilibrium response of the skill distribution of vacancies towards the higher skill. In this sense, the program has a multiplier effect at the aggregate level.

To what extent do the above treatment effects agree with microeconometric studies? To date, a few studies have examined the effects of adult education in Sweden on individual labor market outcomes. Several studies compare individual labor market outcomes between unemployed individuals who enroll in KL and unemployed individuals who enroll in labor market training, using propensity score matching or IV methods (see e.g. Axelsson and Westerlund, 1999, and Stenberg, 2003). The results depend strongly on the outcome measure, the evaluation method, and the type of labor market training and subpopulation considered. ${ }^{4}$ Albrecht, Van den Berg, and Vroman (2005) perform difference-indifferences and conditional probit analyses. The simulated effect on employment in the current paper is in agreement with their econometric results for young men. Our current finding that the average "partial" effect on wages is positive and bounded from above by the average equilibrium effect on wages is harder to reconcile with the corresponding econometric results that suggest that there is no significant treatment effect on the treated. However, the "post-program" year used in our earlier microeconometric analysis was 2000 and fell in the middle of the era during which KL ran. In 2000, not enough time had passed to allow the full effects of the program to come to fruition. Indeed, in 2000, individuals whose skills were upgraded may not even have had enough time to leave their

\footnotetext{
${ }^{4}$ For the US, Jacobson, LaLonde and Sullivan (2003) estimate the effects of adult education using a sample of displaced prime-aged workers. They find sizable returns. However, as Björklund et al. (2004) argue, generalizing from evidence on US adult education programs is difficult because there are so many low-skilled individuals in the US, many of whom may have had insufficient human capital investment opportunities earlier in life. Indeed, the skill distribution in Sweden is more compressed than in the US (see Björklund et al., 2004, for an exposition).
} 
post-program dip. ${ }^{5}$ Employment effects may reveal themselves earlier than wage effects if the wage setting institutions do not allow for swift wage adjustments. ${ }^{6}$ In a more recent study, Stenberg and Westerlund (2006) use data for the period 1993 through 2003 and find that the annual earnings effects for participants is significantly positive if the length of stay in KL exceeds one semester.

To get provide further insight into the aggregate effects of the KL program, we look at changes in the Swedish labor market from 1996 to 2004 in the next section.

\subsection{The aggregate changes in the Swedish labor market from pre-KL to post-KL}

Our analysis of 1996 started with data on unemployment by education category. Insofar as the economy is able to adjust, our model predicts that the upgrading of the skills of a large fraction of the low-skill work force eventually (in steady-state equilibrium) leads to an economy with more medium-skill jobs and fewer low-skill jobs, with wage increases for those who make the skill upgrade. To examine this, we now compare data from 1996 and 2004. As shown earlier in the paper, data for 1996 from AKU Tables 43 and 48, show

\begin{tabular}{|c|c|c|c|c|c|c|}
\hline SUN Codes & 1 & 2 & 3 & 4 & 5 & Total \\
\hline LF in 100's & 4320 & 4544 & 12346 & 5870 & 5649 & 32729 \\
\hline U in 100's & 398 & 431 & 996 & 448 & 249 & 2522 \\
\hline U rates & .092 & .095 & .081 & .076 & .044 & .077 \\
\hline
\end{tabular}

These imply that $p_{1}=0.648, p_{2}=0.352, \gamma_{1}=0.724, \gamma_{2}=0.276$ and average skill-specific unemployment rates of $u_{1}=0.086$ and $u_{2}=0.060$. We used AKU Table 49 to derive exit rates out of unemployment for low- and medium-skill workers of 1.899 and 2.163, respectively. We used the "Totalt" column of Table 4 of Lönestatistisk Årsbok for 1996 to set the wages as $w_{11}=177,600, w_{21}=$ $186,000, w_{22}=210,000$.

\footnotetext{
${ }^{5}$ Also, the sample sizes in the econometric analysis in Albrecht, Van den Berg and Vroman (2005) may have been too small to detect significant effects.

${ }^{6}$ Of course, the simulated equilibrium wage effects may be affected by misspecification of the equilibrium model. An equilibrium model with skill heterogeneity along the lines of Heckman, Lochner and Taber (1998), for instance, would give different results because of the different way in which the production technology is modeled. In Heckman, Lochner and Taber (1998), a rise in tuition subsidies for college students increases the supply of college graduates, but this in turn reduces their wages.
} 
For 2004, AKU Tables 43 and 48 give

\begin{tabular}{|c|c|c|c|c|c|c|}
\hline SUN Codes & 1 & 2 & 3 & 4 & 5 & Total \\
\hline LF in 100's & 1968 & 3774 & 12184 & 7323 & 6197 & 31446 \\
\hline U in 100's & 129 & 202 & 607 & 394 & 255 & 1587 \\
\hline U rates & .066 & .054 & .050 & .054 & .041 & .050 \\
\hline
\end{tabular}

These imply that $p_{1}=0.570$ and $p_{2}=0.430$. In addition, the fraction of unemployment accounted for by low-skill workers $\gamma_{1}$ equals 0.591 (implying that $\gamma_{2}=0.409$ ), and the average skill-specific unemployment rates are $u_{1}=0.052$ and $u_{2}=0.048$. Wages for 2004 by education category are not available, but using a similar rough estimate for wages by skill from Table 5a of the Lönestatistisk Årsbok for 2003 gives $w_{11}=231,600, w_{21}=246,000, w_{22}=285,600$. After deflating the wages for 1996 and 2003 (using 1983 SEK), we have

\begin{tabular}{|c|c|c|c|}
\hline & $w_{11}$ & $w_{21}$ & $w_{22}$ \\
\hline Real Wages 2003 & 486128 & 516354 & 599474 \\
\hline Real Wage 1996 & 343656 & 359910 & 406350 \\
\hline Percent Change & $41.5 \%$ & $43.5 \%$ & $47.5 \%$ \\
\hline
\end{tabular}

The simulations given in Section 4 were for a program that changed the proportion of low-skill workers to $p_{1}=0.6$ and to $p_{1}=0.55$. In the actual Swedish economy, the proportion of low-skill workers declined to a figure between the two simulations. This actual decline was in part due to retirements of older, lesseducated workers and entry of younger and better-educated workers rather than to the KL program.

Of course, any comparison of simulation outcomes and post-program outcomes is hampered by external long-run trends and short-run cycles in the outcomes, as those are not incorporated into the equilibrium model. It therefore makes sense to focus on the relative ordering of effects across groups of workers. For a program that resulted in $p_{1}=0.6$, the simulations predicted ${ }^{7}$ that $\gamma_{1}=0.710, \gamma_{2}=0.289$, $u_{1}=0.092$ and $u_{2}=0.056$. In the 2004 data, we see that $\gamma_{1}$ fell and $\gamma_{2}$ rose as predicted, but the effects were much larger than in the simulations. We also see that because overall unemployment fell, the unemployment rates among both the low skilled and medium skilled fell. It appears that, in contrast to the model predictions, the fall was greater among the low skilled than among the medium skilled. In any case, from the unemployment rates it is fairly clear that 2004

\footnotetext{
${ }^{7}$ For $p_{1}=0.55$ the predications are qualitatively similar.
} 
witnessed a much more favorable labor market than 1996, and this complicates our assessments. With respect to wages, the percent changes are in the correct order. The simulations predicted that real wages for low-skill workers would fall. They rose, but this is likely due to an increasing trend in over-all productivity.

\section{Conclusions}

Our theoretical analysis of an equilibrium search model with heterogeneity, along with the calibration of the model and the simulation of the policy change, provide some interesting insights into the equilibrium effects of the knowledge lift program. Most notably, according to the model, the program should generate an equilibrium change in the skill distribution of vacancies towards higher skills. In our simulations, as the fraction of medium-skill workers in the labor force increases at the expense of the fraction of low-skill workers, the fraction of vacancies tailored towards the medium-skill workers increases commensurately, almost one-for-one. For each outcome measure, the treated gain most from the program. Those who have always been medium skill also benefit, whereas those who remain low skill suffer. Moreover, the equilibrium effects are always a factor 1.5 to 2 times larger than the "partial" effects.

Will the knowledge lift program have such large equilibrium effects in the long run? This is of course difficult to assess. In the short run, i.e., by 2004, we see some changes in the relative wages for the low- versus middle-skill workers in Sweden. Should these be attributed to KL? Rather than make large claims for our model, we would rather argue that such macroeconomic analysis focuses attention on effects beyond the impacts on those directly enrolled in the training program. For large programs such as KL, this perspective is an important one to keep in mind, and we believe that models such as ours are useful in pointing this out. 


\section{References}

Albrecht, J.W. and S.B. Vroman (2002), "A matching model with endogenous skill requirements", International Economic Review, 43, 283-305.

Albrecht, J., G.J. van den Berg, and S. Vroman (2005), The Knowledge Lift: The Swedish adult education program that aimed to eliminate low worker skills, Research report, IFAU, Uppsala.

Axelsson, R. and O. Westerlund (1999), "Participants in the Knowledge Lift in autumn 1997 and comparison groups: labor market and income conditions before education", Working paper, Umeå University, Umeå (in Swedish).

Björklund, A., P.A. Edin, P. Fredriksson, and A. Krueger (2004), "Education, equality, and efficiency - An analysis of Swedish school reforms during the 1990s", Working paper, IFAU, Uppsala.

Ekström, E. (2003), "Essays on inequality and education", Working paper, Uppsala University, Uppsala.

Fay, R.G. (1996), "Enhancing the effectiveness of active labour market policies: Evidence from programme evaluations in OECD countries", Working paper, OECD, Paris.

Friberg, N. (2000), "Thematic review on adult learning: Sweden", Working paper, OECD, Paris.

Heckman, J.J., R.J. LaLonde, and J.A. Smith (1999), "The economics and econometrics of active labor market programs", in O. Ashenfelter and D. Card, editors, Handbook of Labor Economics, Volume III, North-Holland, Amsterdam.

Heckman, J.J., L. Lochner, and C. Taber (1998), "General equilibrium treatment effects: a study of tuition policy", American Economic Review, 88, 381-386.

Jacobson, L., R.J. LaLonde, and D. Sullivan (2003), "Should we teach old dogs new tricks? The impact of community college retraining on older displaced workers", Working paper, Federal Reserve Bank, Chicago.

Lise, J., S. Seitz, and J. Smith (2002), "Equilibrium policy experiments and the evaluation of social programs", Working paper, Queen's University, Kingston.

Martin, J.P. and D. Grubb (2001), "What works and for whom: a review of OECD countries' experiences with active labour market policies", Swedish Economic Policy Review, 8, 9-56.

Ministry of Education (1998), "Adult education and life long learning. the situation before and during the first year of the Knowledge Lift", Working paper, 
Ministry of Education, Sweden, Stockholm (in Swedish).

Ministry of Industry (2001), "Sweden's action plan for employment", Working paper, Ministry of Industry, Sweden, Stockholm.

National Agency for Education (1999), The Adult Education Initiative, National Agency for Education, Stockholm.

OECD (2004), Employment Outlook 2004, OECD, Paris.

Petrongolo, B. and C.A. Pissarides (2001), "Looking into the black box: a survey of the matching function", Journal of Economic Literature, 39, 390-431.

Skolverket (2001), "The Knowledge Lift and upper secondary adult education Fall 2000", Working paper, Skolverket, Stockholm (in Swedish).

Statistics Sweden (1997a), "Labor force survey, yearly average 1996", Working paper, Statistics Sweden, Örebro (in Swedish).

Statistics Sweden (1997b), Wage statistics yearbook 1996, Statistics Sweden Publication Service, Örebro (in Swedish).

Statskontoret (1999), "How much does the Knowledge Lift cost?", Working paper, Statskontoret, Stockholm (in Swedish).

Stenberg, A. (2003), "An evaluation of the adult education initiative relative labor market training", Working paper, Umeå University, Umeå.

Stenberg, A. and O. Westerlund (2006), Does comprehensive education work for the long-term unemployed?, Working paper, SOFI, Stockholm University, Stockholm. 


\section{Appendix}

\section{Appendix 1. Calibration of the ex post segmentation equi- librium}

In an ex post segmentation equilibrium, there is no steady-state condition for the flows of medium-skill workers in and out of low-skill jobs. We therefore assume that $\beta=0.5$. In this case, the inequalities on $U$ are

$$
\begin{aligned}
& s_{1}-c_{1}<r U\left(s_{2}\right) \\
& s_{1}-c_{1} \geq r U\left(s_{1}\right) \\
& s_{2}-c_{2} \geq r U\left(s_{2}\right) .
\end{aligned}
$$

The exit rates for this case are

\begin{tabular}{|c|c|c|c|}
\hline$m(\theta)=4.0$ & $\phi_{1}$ & $=.463$ & $\phi_{2}$ \\
\hline$\overline{\delta_{1}}$ & $\delta_{2}$ & $e_{11}$ & $e_{22}$ \\
\hline .176 & .139 & .592 & .331 \\
\hline
\end{tabular}

$$
\begin{array}{|l|}
\hline m(\theta) \phi_{1}=1.867 \\
\hline m(\theta) \phi_{2}=2.163 \\
\hline
\end{array}
$$

These imply

Step 2 yields

\begin{tabular}{|l|l|l|l|}
\hline$s_{1}-c_{1}$ & $s_{2}-c_{2}$ & $r U\left(s_{1}\right)$ & $r U\left(s_{2}\right)$ \\
\hline 188140 & 207480 & 167130 & 188520 \\
\hline
\end{tabular}

Note that $s_{1}-c<r U\left(s_{2}\right)$, which is consistent with ex post segmentation.

Finally, in this case, $m(\theta)=4.03$, so $\theta=.65$ and $\frac{m(\theta)}{\theta}=6.20$. The zero-value conditions imply

\begin{tabular}{|c|c|c|c|c|}
\hline$\theta$ & $c_{1}$ & $c_{2}$ & $s_{1}$ & $s_{2}$ \\
\hline .650 & 209462 & 85880 & 397602 & 293360 \\
\hline
\end{tabular}

Clearly, the cost and productivity parameters are in the wrong order. 


\section{Appendix 2. Simulation equations}

The two steady-state equations equate the flows into and out of unemployment for each of the skill levels. These two equations can be written as

$$
\begin{aligned}
& \phi_{1} m(\theta) \gamma_{1} u=\delta_{1}\left(p_{1}-\gamma_{1} u\right) \\
& m(\theta) \gamma_{2} u\left(\frac{\phi_{1}}{\delta_{1}}+\frac{\phi_{2}}{\delta_{2}}\right)=p_{2}-\gamma_{2} u .
\end{aligned}
$$

In the cross-skill matching equilibrium, the two unemployment values are

$$
\begin{aligned}
& r U\left(s_{1}\right)=\frac{b R_{1}+m(\theta) \phi_{1} \beta S_{1}}{R_{1}+m(\theta) \phi_{1} \beta} \\
& r U\left(s_{2}\right)=\frac{b R_{1} R_{2}+\beta m(\theta)\left[\phi_{1} R_{2} S_{1}+\phi_{2} R_{1} S_{2}\right]}{R_{1} R_{2}+\beta m(\theta)\left(\phi_{1} R_{2}+\phi_{2} R_{1}\right)},
\end{aligned}
$$

where $S_{1}=s_{1}-c_{1}$, and $S_{2}=s_{2}-c_{2}, R_{1}=r+\delta_{1}$, and $R_{2}=r+\delta_{2}$.

The zero vacancy value equations for this equilibrium type are

$$
\begin{aligned}
& r V\left(s_{1}\right)=-c_{1}+\frac{m(\theta)}{\theta}\left\{\gamma_{1}\left[\frac{(1-\beta)\left[S_{1}-r U\left(s_{1}\right)\right]}{R_{1}}-V\left(s_{1}\right)\right]+\gamma_{2}\left[\frac{(1-\beta)\left[S_{1}-r U\left(s_{2}\right)\right]}{R_{1}}-V\left(s_{1}\right)\right]\right\} \\
& r V\left(s_{2}\right)=-c_{2}+\frac{m(\theta) \gamma_{2}}{\theta}\left[\frac{\left.(1-\beta) S_{2}-r U\left(s_{2}\right)\right]}{R_{2}}-V\left(s_{2}\right)\right] .
\end{aligned}
$$

Setting $V\left(s_{1}\right)=V\left(s_{2}\right)=0$ and substituting for the unemployment values gives

$$
\begin{aligned}
& \frac{c_{1} R_{1} \theta}{(1-\beta) m(\theta)}=\frac{\gamma_{1}\left(S_{1}-b\right) R_{1}}{R_{1}+m(\theta) \phi_{1} \beta}+\gamma_{2}\left(\frac{\left(S_{1}-b\right) R_{1} R_{2}+\beta m(\theta) \phi_{2} R_{1}\left(S_{1}-S_{2}\right)}{R_{1} R_{2}+\beta m(\theta)\left(\phi_{1} R_{2}+\phi_{2} R_{1}\right)}\right) \\
& \frac{c_{2} R_{2} \theta}{(1-\beta) m(\theta)}=\gamma_{2}\left[\frac{\left(S_{2}-b\right) R_{1} R_{2}+\beta m(\theta) \phi_{1} R_{2}\left(S_{2}-S_{1}\right)}{R_{1} R_{2}+\beta m(\theta)\left(\phi_{1} R_{2}+\phi_{2} R_{1}\right)}\right] .
\end{aligned}
$$

These two equations, along with the two steady-state equations, are the equations that must be solved for the equilibrium. After solving for the equilibrium, the wages can be found by using the wage equations

$$
\begin{aligned}
& w\left(s_{1}, s_{1}\right)=\beta S_{1}+(1-\beta) r U\left(s_{1}\right) \\
& w\left(s_{2}, s_{1}\right)=\beta S_{1}+(1-\beta) r U\left(s_{2}\right) \\
& w\left(s_{2}, s_{2}\right)=\beta S_{2}+(1-\beta) r U\left(s_{2}\right) .
\end{aligned}
$$

